\title{
O curso de Deleuze sobre a filosofia política de Rousseau
}

Américo Grisotto

Professor Adjunto da Universidade Estadual de Londrina

\section{Resumo}

Neste artigo, o autor apresenta as notas que Gilles Deleuze preparou para um curso sobre a filosofia política de Rousseau, oferecido na Sorbonne, no ano acadêmico de 1959-1960. Essas notas foram traduzidas pelo autor deste artigo e aparecem pela primeira vez em português, como homenagem da Revista Filosofia e Educação ao tricentenário do nascimento de Rousseau, bem como em lembrança dos 250 anos de publicação de Emílio, ou Da Educação.

Palavras-chave: Rousseau; Deleuze; filosofia política; educação.

\begin{abstract}
In this article, the author presents the notes that Gilles Deleuze prepared for a course on political philosophy of Rousseau, offered at the Sorbonne in the academic year 1959-1960. These notes were translated by the author and first appear in Portuguese, in homage of the journal Philosophy and Education at the tercentenary of the birth of Rousseau, and in remembrance of the 250 years of publication of his work, Emile.
\end{abstract}

Keywords: Rousseau; Deleuze; political philosophy; education. 


\section{Considerações iniciais}

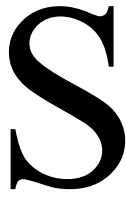

e retomar um autor a partir de aspectos que consideramos notáveis é uma forma de homenageá-lo, foi isto que fez Deleuze, no nosso ponto de vista, quando ministrou, como professor assistente na Sorbonne de 1959-1960, o curso ${ }^{1}$ sobre a filosofia política de Rousseau. No entanto, devido à natureza da homenagem nesse dossiê, pode haver quem se pergunte: o que teria a ver a filosofia política de Rousseau e a temática proposta? Afinal, não se trata, principalmente, da comemoração em torno dos 300 anos do seu nascimento e dos 250 anos da publicação do Emílio, em que a publicação do Contrato Social, no mesmo ano, é mero detalhe?

Sem dúvida, o Emílio é o ponto central, como o é a educação. Os artigos reunidos aqui almejam atingir esse ponto. Todavia, em Rousseau, apartar o Contrato Social publicado em abril de 1962 e o Emílio, publicado em maio do mesmo ano, não é uma tarefa simples e nem mesmo a mais interessante. Há elementos na relação entre essas duas obras, bem como na relação entre educação e política em Rousseau, que não estão aquém desta coincidência temporal.

Aliás, numa hipótese que aventamos inspirada nas ideias de Deleuze desenvolvidas neste curso, a educação ${ }^{2}$ traz consigo, por um lado, - tendo

1 Do qual traduzimos, logo após estas considerações iniciais, o resumo datilografado dispondo-se num conjunto de notas das aulas divididas, respectivamente, em temáticas e tópicos de desenvolvimento, a partir dos quais Deleuze encadeia uma série de contextualizações aos elementos que seleciona das obras de Rousseau, de maneira a confrontá-los com as perspectivas de outros pensadores e obras. Devido a este aspecto, este curso, além de exigir um acesso ao contexto a que se referem estas obras, nos convoca em contrapartida - pela indicação e seleção das passagens - ao exercício do pensamento.

2 À educação estaria destinada a tarefa de envolver a todos na ocupação que nos torna bons porque em consonância com os interesses que nos movem (estratégia de dispersão espacial materializada nos múltiplos interesses advindos das nossas afeições), enquanto que se experimenta entre nós o contrário, ou seja, o fomento do bom senso, ou do senso comum, cuja estratégia afunila a todos num único interesse regido politicamente, socialmente, civilmente, por forças que se coadunam entre Estado e o Mercado (subtração da nossa

Filosofia e Educação - ISSN 1984-9605 - Volume 4, Número 2

Outubro de 2012 - Março de 2013 
em conta o uso que este pensador faz da Nova Heloísa, Confissões, Devaneios de um caminhante Solitário entre outras obras - uma dimensão estratégica, porque colocada em ação por nossas afeições ${ }^{3}$, ou por um processo físico, psíquico, filosófico, que se utiliza do nosso interesse em sermos bons, e, por outro lado, se considerarmos o uso que Deleuze faz do Contrato Social, mas também do Discurso sobre as Desigualdades e do embate entre Rousseau e Hobbes - que a dimensão política supõe a educação, pois, em seu terreno, é possível que se construa algo de interessante com o que nos afeiçoa; processo intransferível de trabalho com nossas necessidades e que, ao mesmo tempo, pretende dar conta de nossas vontades $^{4}$ configurando outras relações no campo da política.

Para citar a seguir apenas um único trecho, um tópico de aula, de que o pensador francês se utiliza ao tratar da filosofia de Rousseau, dizendo justamente a respeito de algo que nos desviaria do vício, bem como do interesse em sermos maus, numa espécie de antídoto tanto educacional, quanto político, teríamos:

[...] A bondade original. É a bondade da alma em estado de natureza. Afirmação desta bondade que nunca está separada de uma afirmação determinista. São as situações que determinam nossas afeições. A alma é inicialmente a faculdade do sentir, não a

potência e força afetiva da relação direta com as coisas a nos envolver e ocupar, dispersivamente, pela ótica dos múltiplos interesses); a escola, em consonância com a educação e em oposição ao sentido único que a agencia atualmente seria o espaço no interior da sociedade e fora dela, isto é, com condições de se tornar um lugar do cultivo e de experimentação do conhecimento, e não lugar de aquisição do mesmo para finalidades que desconhecemos e que não nos interessam diretamente.

3 Podem ser entendidas aqui, bem como no curso ministrado por Deleuze, como afecções no sentido do modo peculiar com que somos tomados problematicamente, determinadamente, pelo que nos afeiçoamos. Especificamente, neste caso, tem a ver como o nosso processo de subjetivação consistindo na própria dimensão política e que pode desembocar numa ação pela junção de afeições com outras afeições a nos ocupar afirmativamente.

4 Como não é possível representar a vontade e nossas afeições têm ligação direta com ela, uma política futura faria com que nos ocupássemos novamente com o estado de natureza, em que seríamos respeitados na nossa vontade porque somente nós nos obrigaríamos.

Filosofia e Educação - ISSN 1984-9605 - Volume 4, Número 2

Outubro de 2012 - Março de 2013 
razão. O que aparece inicialmente, é a 'dependência das coisas', que é natural. Esta afirmação engendra a da bondade original, pois em estado de natureza, todas as nossas ações são boas, isto é, apropriadas ao objeto (para dizer de outra forma é a transcrição naturalista da concepção: realidade $=$ perfeição). [...] Neste tipo de bondade, cada um é um todo para si. Ela só se constitui como uma com o sentimento de existência. Todavia há uma diversidade natural nas almas vida da diferença das faculdades fundamentais.

De ponta a ponta deste curso ministrado por Deleuze a imbricação entre educação e política tem a ver com o que nos determina afirmativamente, com o que nos afeiçoamos diretamente, ou ainda com o que nos afeiçoamos sem mediação, não transferindo a ninguém a tarefa de darmos conta de nossa dependência em relação às coisas, àquilo que nos é natural. A propósito, é o que o mesmo Deleuze expressa, em outro registro, através de uma regra que atravessa o Emílio, finalizando, em 1962, um artigo em homenagem a Rousseau "Jean-Jacques Rousseau - Precursor de Kafka, de Céline e de Ponge"s:

A verdadeira correção pedagógica consiste em subordinar a relação dos homens à relação dos homens com as coisas. [...] daí a famosa regra do Emílio, regra que requer apenas vigor: jamais trazer as coisas para a criança, mas levar a criança até as coisas (2006, p. 77).

Avançando nesta hipótese, uma educação que é ao mesmo tempo política só se faria a partir do que pode ser sentido ${ }^{6}$, experimentado singularmente no pensamento, ou quando nos servíssemos do antídoto que nos toma afirmativamente, nos relacionamento diretamente, seletivamente

5 Cf.: DELEUZE, Gilles. A ilha deserta: e outros textos. Edição preparada por David Lapoujade; organização da edição brasileira e revisão técnica Luiz B. L. Orlandi. São Paulo: Iluminuras, 2006, p. 73-77. Aliás, esse artigo que citamos, foi redigido por Deleuze há 50 anos por ocasião do $250^{\circ}$ aniversário do nascimento de Rousseau e que, certamente, não deixou de ser uma comemoração quanto aos 200 anos da publicação das obras Contrato e Emílio.

6 Cf.: DELEUZE, Gilles. Diferença e repetição. Trad. Luiz Orlandi, Roberto Machado. Rio de Janeiro: Graal, 1998, p. 203: o ser do sensível opõe-se à recognição, ao retorno do mesmo. O pensamento encontra-se numa espécie de latência quando não se operacionaliza, não se põe em devir pelo que só pode ser sentido.

Filosofia e Educação - ISSN 1984-9605 - Volume 4, Número 2

Outubro de 2012 - Março de 2013 
com a matéria do mundo, no envolvimento com nossas necessidades, e não fazendo o oposto disto no que chamamos de política, de educação, pois na política, na sociedade, na educação principalmente - tal e qual as encontramos no nosso meio como formas que unilateralizam modos de pensar em detrimento da diversidade que desconhecemos nestas dimensões - de fato nos escravizaríamos. Em outras palavras, o Emílio, nesse curso, atravessa as obras de Rousseau interpretadas por Deleuze trazendo elementos do que só pode ser sentido, experienciado, selecionado no pensamento tratando-se da própria política, isto é, ocupação com o que se encontra mais próximo do nosso interesse em sermos bons e do estado de natureza ${ }^{7}$, cuja auto-suficiência pelo trabalho com nossa dependência nos desviaria da fatalidade presente na política e na sociedade vigentes - nos tornando afeitos, em outro nível, a este tipo de relação política e social. Nas palavras de Deleuze (2006) em seu artigo em homenagem a Rousseau:

O estado de natureza não é somente um estado de independência, mas de isolamento. Um dos temas constantes de Rousseau é que a necessidade não é um fator de aproximação: ela não reúne, ao contrário, isola. Por serem moderadas, nossas necessidades no estado de natureza entram necessariamente em uma espécie de equilíbrio com nossos poderes, adquirem uma espécie de autosuficiência (p. 73).

De outro modo, tal circunstância nos permitiria o pleno exercício de nossas forças, porque acompanhadas das nossas sinceras e autênticas afeições. O que significa que não se tratam de afeições pela metade, mas determinantes de um contrato consigo, de quem se sente envolvido com o estado de natureza, ou com um interesse em permanecer bom no que o tomou em favor da sua própria cooperação. Assim, em termos de contrato e pelo critério do que só pode ser sentido por nós no uso necessário do

$7 \mathrm{O}$ estado de natureza como circunstância em que solitariamente daríamos conta de nossas necessidades, impõe-se como instância pré-política, porque pré-social, pré-cívica. Trata-se de um preparo para o que está em vias de se constituir em nós neste campo de experimentação. Por este motivo, é lugar de pura potência, de pura força.

Filosofia e Educação - ISSN 1984-9605 - Volume 4, Número 2

Outubro de 2012 - Março de 2013 
pensamento, antes de nos associarmos com o que desconhecemos em nós, convém que estejamos associados experiencialmente, seletivamente, àquilo que prescreve nossa condição de superação de uma dependência diante do mundo material prioritariamente, e as afeições têm relação direta com este aspecto. Tal movimento é que nos lançaria no campo do que seria a política

Desta maneira, se as nossas afeições tendem, hoje em dia, tanto a artificialidade, quanto a serem regidas por uma mistificação, quais seriam as afeições que nos são próprias, ou melhor, quais as afeições que nos tomam no pensamento e nos cobram um empenho? Diante de tal problema, haja vista, na atualidade, as investidas da mídia sobre o nosso desejo, em que, de fato, tudo deixa a desejar e se move pela exploração de nossas necessidades mais elementares, tais indagações nos são bem-vindas se nos dispusermos uma vez livres porque determinados a pensar - a criar filosoficamente, conceitualmente, um recomeço para o que chamamos de educação, o que não deixa de ser, num mesmo antídoto próprio da bondade que nos é natural, um recomeço para outras relações na esfera da política, do social e do cívico

Tal sugestão nos leva a pensar que os alunos, ao se endereçarem vazios de suas afeições, de seus problemas às salas de aula, estariam mais bem resolvidos se, em primeiro plano, "rompessem" - porque não lhes cabe outra saída - com o interdito que os impedem de acessar diretamente as bibliotecas, os laboratórios, as salas de leitura, de estudo, de reuniões da escola e, uma vez levados às coisas, às matérias-primas disponíveis da cultura, escolhessem (o que não poderiam escolher senão diferentemente) as ferramentas para as temáticas, as problemáticas às quais paradoxalmente livremente condenados, a ponto de tomá-las por objeto de estudo e, em segundo plano, que fossem informados se há, ainda, outros recursos que poderiam contribuir nesta tarefa nos ambientes de sala de aula e conjuntamente com o que os professores que têm algo a lhes oferecer. Segundo esta opção, é possível ter um professor que tomou para si, estuda,

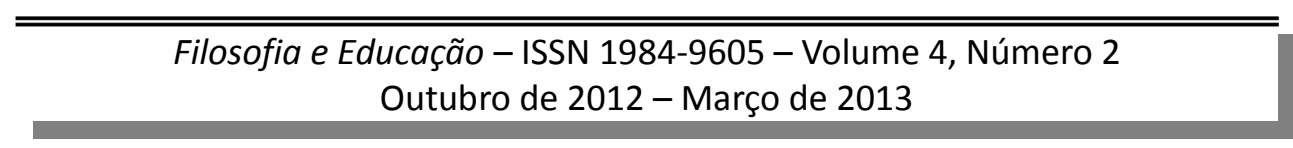


pesquisa e ensina determinadas temáticas, em interlocução com um aluno, ou um grupo deles, que têm estudado, pesquisado, a partir de problemas que os determinam afirmativamente, e, nas quais, não teriam como não avançar. Aprendizagem, diálogo entre "iguais" pela ótica da dispersão e do deslocamento dos interesses, em que ganha a ordem do dia a múltiplo do pensamento que, até então, trazia a superioridade do interesse comum (movimento de indiferença às determinações afirmativas que nos tomam nas nossas afeições). Assim, quem se dirigisse à escola se dirigiria a um lugar que envolveria quem dele participa - em favor da superação do atual estado de coisas que se lhes impõe - e, por isto mesmo, fora da política e da sociedade, e, ao mesmo tempo, em relação direta com estas dimensões pelo critério dispersivo e polarizado do envolvimento com a matéria que nos ocupa e diferencia (problematicamente), instaurando-se como a própria relação com a política, o social e o cívico.

Diferentemente de estarmos formando atualmente, através da educação, o macro e o micro empreendedor, com todos os mecanismos que se alimentam deste tipo de descompensação, tornando-nos maus, seria mais notável que nos colocássemos, pela via do que nos inclui neste imbróglio e nos fortalece quanto o tomamos como problema, a tarefa da auto-suficiência formativa enquanto utilização política deste fortalecimento, de modo que este esforço voluntário, pelo que pensamos necessário à educação e à política, perdure. Bem a propósito destas questões, embora a citação seja um tanto longa:

É na relação com os objetos, com os lugares, por exemplo um bosque, que conhecemos a fuga do tempo e que saberemos, enfim, querer no futuro, em lugar de nos apaixonarmos no passado. Isso é o que Rousseau chamava de 'o materialismo do sábio', ou cobrir o passado com o presente. [...] Os dois pólos da obra filosófica de Rousseau são o Emílio e o Contrato social.

O mal, na sociedade contemporânea, é que nós não somos mais nem homem privado nem cidadão: o homem tornou-se 'homo 
oeconomicus', isto é, 'burguês', animado pelo dinheiro. As situações em que há interesse em sermos maus implicam sempre relações de opressão, nas quais o homem entra em relação com o homem para obedecer ou comandar, senhor ou escravo. O Emílio é a constituição do homem privado, o Contrato social, a do cidadão. A primeira regra pedagógica de Rousseau é esta: nós chegaremos a nos constituir enquanto homens privados quando restaurarmos nossa relação natural com as coisas, com isso preservando-nos das relações artificiais demasiado humanas que, desde a infância, acarretam em nós um perigosa tendência a comandar. (E é a mesma tendência que nos faz escravo e que nos faz tirano) (DELEUZE, 2006, p. 77).

Nestes termos, a educação como espaço de ensaio da dimensão prépolítica $^{8}$, pré-social, pré-cívica, consiste na relação direta, afeiçoada ${ }^{9}$, problematizante, com as coisas, com o mundo material e físico, com os objetos do comportamento moral, com os objetos da cultura, do pensamento etc. e implica, portanto, nas metamorfoses deste meio propiciadas pelas afeições, pelo impulso da bondade natural que nos singulariza e que nos coloca diferentemente diante da política, da sociedade, do cívico. Processo ${ }^{10}$

8 Entendemos por dimensão pré-política o processo educacional intransferível, afirmativo, auto-formativo (trabalho com o que nos determina porque nos afeiçoa) na constituição de nossa auto-suficiência.

9 Neste caso poderíamos ter utilizado afetiva ao invés de afeiçoada. A título de esclarecimento, a afetividade, no nosso ponto de vista, teria mais a ver com o que caracteriza as relações interpessoais no tipo de sociedade que vivemos - tanto é que há, inclusive segundo uma determinada interpretação dos seguidores de Rousseau, uma educação que se daria através do afeto, do amor, do carinho, aproveitando-se daquilo que as pessoas não se propõe a resolver no reino da necessidade, constituindo-se pela exploração da carência deste aspecto, enquanto que o afeiçoamento diz respeito a um certo apego afirmativo pela relação direta que estabelecemos com as coisas, com o que nos determina e, ao mesmo tempo, com àquilo que nos aparelha e nos torna afirmativos na utilização de nossas forças. Processo este de uma educação solitária na relação com o mundo físico, provocando uma dispersão de interesses latentes no pensamento e, em igual medida, capaz de desarticular os mecanismos de exploração que se alimentam da descompensação propiciada por este tipo de educação. Assim, como o sentido que queremos dar a esta explanação vai na direção de que a relação pré-política (afetuosa) com as coisas prescinde a relação pedagógica (afetiva) com a sociedade, com a política etc. pensamos ser mais importante que as pessoas, no processo de educação, equacionem e avancem politicamente neste tipo de problematização filosófica da relação consigo mesmas no que lhes é inalienável para que, adentrando nas relações interpessoais, não as tornem essencialmente o jogo da exploração de suas vontades, desejos e necessidades.

10 Um pleno ocupar-se imaginativo, experimental, isto é, um regime das afeições que nos impõem um contrato interessado com nós mesmos em termos do necessário para nossa auto-suficiência em sentido amplo e de tal modo que este contrato prossiga. Por este

Filosofia e Educação - ISSN 1984-9605 - Volume 4, Número 2

Outubro de 2012 - Março de 2013 
de envolvimento político que nos associa ao interesse de sermos bons e a estender-se - como possibilidade do seu acontecimento - enquanto durar nossa dependência em relação às coisas, ou com a força que nos convoca e toma afeiçoadamente, efetivamente no pensamento. Por isto:

O homem privado é aquele que, devido à sua relação com as coisas, conjurou a situação infantil que lhe confere o interesse em ser mau. Mas o cidadão é aquele que entra em relações com os homens, onde ele tem exatamente interesse em ser virtuoso. Instaurar uma situação objetiva e atual em que a justiça e o interesse se reconciliem, parecer ser, segundo Rousseau, a tarefa efetivamente política. E a virtude retoma aqui seu sentido mais profundo, que remete à determinação pública do cidadão.

Em suma, por trata-se de algo cuja ênfase encontra-se no processo e inexistente politicamente, socialmente, civicamente, educacionalmente entre nós, nenhum estudante - e neste aspecto nos incluímos todos - se dedicaria aos estudos porque lhe internalizaram a punição, o controle, a culpa etc. e isto porque não abriria mão, não entregaria a ninguém o equacionamento do problema que obstaculiza ${ }^{11}$ seu interesse, sua disposição de viver plenamente e o que lhe permite avançar tornando-se um aliado seu no que se dispõe a trabalhar na sua educação e na maneira como se relaciona com a política, a sociedade, a cidadania. Se tomarmos, novamente, a escola atualmente, é sua função aperfeiçoar o conhecimento a que estamos habituados e alicerce seguro, indiscutível da política, da sociedade e da civilidade a que estamos acostumados e que se fortalece pelo trabalho propositivo com nossas necessidades, vontades e desejos, enquanto que seria mais notável que seu espaço fosse o lugar da problematização e construção do que possamos, de fato, nos admirar cientificamente, artisticamente, filosoficamente, ao

movimento, nos colocaríamos diferentemente diante da atual política, sociedade, e controle cívico.

11 Que dificilmente se diferenciaria, pela objetividade do que é problemático, ou seja, pela nossa não neutralidade diante deste processo, a respeito do problema que mencionamos, da punição, da opressão, do controle etc. que pairam sobre a educação e a política.

Filosofia e Educação - ISSN 1984-9605 - Volume 4, Número 2

Outubro de 2012 - Março de 2013 
trabalhar problematicamente com estas questões. Contraste este que tornaria apenas contados, descritos, passados, os conhecimentos, a cultura, que ocupam hoje em dia as salas de aula, bem como dispensável toda maquinaria punitiva e o poder de polícia característicos da sua apreensão. E isto em favor da ocupação afirmativa, problematizante, com os conhecimentos que tínhamos, ou que temos ainda na mais alta conta, e que, de fato, nos condenam, nos exploram. Neste aspecto, embora sejamos bem intencionados, somos, ao mesmo tempo, condenados à opressão pelo tipo de educação e política que nos afeiçoa a todos, isto é, aquilo de que gostamos nos arma uma cilada, e, paradoxalmente, é de tal cilada que temos de nos ocupar para que, no espaço da escola, não nos furtemos a um desafio, de tomar como matéria de desenvolvimento - como estratégia de autosuficiência - o que nos diferencia neste processo, cujo impulso da construção auto-formativa, inclui conhecer o que desconhecemos, ou o que não criamos ainda - como estratégias de resistência ao estabelecido - nas relações que firmamos, desocupadamente, desafeiçoadamente, com a dimensão política, social, cívica, educacional. Atentando ao que nos diz Deleuze "ao exercer o direito de serem obedecidas, as crianças saem do estado de natureza quase ao nascer" (2006, p. 77). Por entregarmos a outrem o trabalho com nossas afeições ao invés de não abrirmos mão de nos ocuparmos delas, e por uma série de questões que deveríamos nos impor pelo que comprometem a nossa alegria presente e futura, a filosofia, especificamente, tende a ser de grande valia, nos alerta Deleuze através de Rousseau, porque através do exercício deste tipo de pensamento é possível entender, dentre uma infinidade de coisas que nos afetam diretamente, um problema educacional e político como o que nos ocupou até o momento, isto é: o de nos apercebermos como é possível, no âmbito mais elementar da educação e da política que, tão logo quando nascemos, desenvolvamos o interesse em sermos maus?

Filosofia e Educação - ISSN 1984-9605 - Volume 4, Número 2

Outubro de 2012 - Março de 2013 
Retomando o que dissemos inicialmente, retomar seus escritos e os problemas que animaram a sua filosofia, embora haja outras formas de abordar um autor como Rousseau, consiste em homenageá-lo convenientemente. Em sentido contrário, ou o que seria a ausência de homenagem em sentido filosófico, teríamos um posicionamento neutro de tomá-lo a partir de si mesmo, o que significaria reverenciá-lo conjuntamente com o último ponto que fechou sua obra.

Assim, se o movimento em filosofia prossegue, por um lado, é porque a relação com o seu pensamento não é a mesma com a pessoa do filósofo, sujeita aos infortúnios da existência, senão com sua obra, com seus problemas e conceitos filosóficos, que fizeram com que a pessoa se superase a si mesma e, por outro lado, o que permitiu que a obra se desviasse dela mesma, de forma que não se torna-se justamente o que estabeleceu no passado deslocando-se para outros problemas e fazendo, num mesmo movimento, com que o leitor se veja em outra perspectiva que não a mesma com que foi tomado no problema que o deteve no pensamento. A respeito de Rousseau, Deleuze, no seu artigo que citamos há pouco, e considerando a obra do autor genebrino, sem deixar de anunciar também o motivo que o fez escolher (ou ser escolhido pelos problemas da obra rousseauniana), nos diz:

Arriscamo-nos de duas maneiras a ignorar um grande autor. Por exemplo, ao desconhecer sua lógica profunda ou o caráter sistemático de sua obra. (Falamos, então, de suas, "incoerências", como se elas nos dessem um prazer superior.) Ou, de outro modo, ao ignorar sua potência e seu gênio cômicos, de onde a obra retira geralmente o máximo de sua eficácia anticonformista. (Preferimos falar das angústias e do aspecto trágico.) (2006, p. 73).

Por esta orientação e atentos ao movimento de um pensamento que prossegue se servindo da produção filosófica e contra-efetuando o que nos legou esta mesma herança do pensamento em filosofia, podemos nos servir dos tópicos propostos e desenvolvidos por Deleuze, nesse curso a respeito

Filosofia e Educação - ISSN 1984-9605 - Volume 4, Número 2

Outubro de 2012 - Março de 2013 
da obra de Rousseau, e pensarmos filosoficamente a imbricação entre educação e política. De outro modo, se a filosofia nos tem serventia, é para nos darmos conta de problemas que nos forçam a pensar o novo. Em sentido oposto, ao perder seu devir, ela não nos diz mais nada quanto às potencialidades da imanência. A propósito, inaugurar, ou impor-se sempre um novo começo no pensamento, não é esta proposta mais cara à filosofia desde seu nascimento?

A propósito, Deleuze (2012) pensando nesse processo próprio da criação filosófica dirá que, antes que uma filosofia alcance a cor filosófica dos seus traços conceituais, faz-se necessário um longo trabalho na constituição de retratos filosóficos, que seriam retratos das obras dos filósofos a partir de problemas que, nelas, nos interessam. Tal comentário, feito por ele no verbete "História da Filosofia" do seu Abecedário", esclarece o que foi o seu movimento de iniciação na filosofia. Segundo este ponto de vista, tanto a filosofia quanto a pintura compartilham da árdua tarefa na constituição de retratos. Às cores e aos traços vivos que fizeram com que pintores como Gauguin e Van Gogh abraçassem, no final de suas vidas, a loucura e a lucidez, precedeu um processo opaco, pouco vivo, não menos árduo, de anos a fio dedicados à arte do retrato. Da mesma forma, não é possível chegar a traços de expressão conceitual em filosofia sem antes passarmos por um longo trabalho consistindo na arte de retratarmos as obras filosóficas pelos quais simpatizamos. Neste aspecto é que se justifica a presença de Rousseau nos estudos de Deleuze. Uma vez atento a alguns dos traços filosóficos presentes em suas obras, Deleuze não só fez, nesse seu curso, história da filosofia, como foi construindo um filosofar que lhe era próprio. Justamente a este propósito, seria possível imaginar, pela ampla leitura de que são testemunhas as obras por ele lidas e investigadas para

12 Cf.: H de História. In: http://www.ufrgs.br/corpoarteclinica/obra/abc.prn.pdf. Acessado em 29/06/2012.

Filosofia e Educação - ISSN 1984-9605 - Volume 4, Número 2

Outubro de 2012 - Março de 2013 
essas aulas, o que foi o seu esforço até chegar aos momentos de inspiração que lhe oferecessem a possibilidade de trazer, a seus alunos, elementos ainda vivos da filosofia, presentes nas obras de Rousseau.

Em razão disso, através de uma condecoração que fazemos a Rousseau pelo trabalho de Deleuze, fica posto, por um lado, que Rousseau, como autor, não receberia a homenagem de ser retomado e continuar ainda vivo, se sua obra não impusesse a Deleuze o que pensar filosoficamente. Por outro lado, que é a partir de obras do legado histórico em filosofia - pelas quais nos afeiçoamos de alguma maneira - que é possível que se visite e se trabalhe, como exercício filosófico, problemáticas que nos são peculiares e que, pela objetividade do que é problemático em nós, não deixam de ser a nossa maneira de pensarmos filosoficamente.

Este é o mérito do curso de Gilles Deleuze e ele também não seria possível se um autor como Rousseau não tivesse, inicialmente, tomado a dianteira e posto mão à obra diante do estabelecido, dispondo-se a, filosoficamente, propor outras possibilidades para o exercício do pensamento. Indo adiante neste aspecto, o que faz Deleuze não é ressuscitar Rousseau no século vinte, como se a questão consistisse em repaginarmos o legado histórico em filosofia, reeditando-o a partir das balizas que já nos são familiares. Pelo contrário, problemas equacionados nos idos da história filosófica podem ser, uma vez mais, reconstruídos sob novo enfoque, sem que tenhamos que anular nossa vontade diante do que representaram em épocas passadas. No curso proferido por Deleuze, o que ecoa não são as teses da tradição atribuídas a Rousseau, mas a escolha de pontos de vista que o fizeram pensar filosoficamente. Por esta via do pensamento filosófico em movimento, o que entregamos ao leitor já se constitui, pelas possibilidades de apropriação filosófica, bem mais do que um retrato de Rousseau feito por Deleuze.

Filosofia e Educação - ISSN 1984-9605 - Volume 4, Número 2

Outubro de 2012 - Março de 2013 
Assim, num interesse que o ocupou neste curso sobre a filosofia política de Rousseau, bem como no artigo que escreveu em sua homenagem, justifica-se a sua recomendação de que, por algumas razões que chamaram sua atenção, relativas à mistificação na separação dos poderes; à República como sendo um único poder, o legislativo; ao conceito de lei a dominar a reflexão filosófica até os dias de hoje “[...] um aniversário de Rousseau é a ocasião certa de ler ou de reler o Contrato social” (2006, p. 77), recomendação esta à qual acrescentamos a ocasião de ler ou reler o Emílio como uma obra que pensando filosoficamente a educação, diz dos nossos interesses (das nossas afeições, vontades, desejos), dos conceitos filosóficos de bondade, de virtude, a nos deslocarem das relações de dominação quando somos explorados em nossa boa fé devido a nossas necessidades e, por este motivo de opressão, alimenta em nós o interesse em sermos maus para a esfera de outra aposta, bem mais interessante, de investir filosoficamente no que nos pega e surpreende pensando quando sentimos.

Enfim, com a intenção de fazermos jus a uma homenagem que convenha a Rousseau ${ }^{13}$, oferecemos ao leitor um presente que não podia ser outro se não um presente de natureza filosófica, em que as mesmas mãos de ferro que nos prendem ao reino da necessidade são as mesmas que sacodem o copo dos dados do acaso ${ }^{14}$ e reinventam, artisticamente, afirmativamente, filosoficamente, a realidade que tanto criticamos sem nela intervir.

13 Em alguns momentos em suas obras, Rousseau rejeitou o título de filósofo e isto, muito provavelmente, em favor de um pensamento filosófico disposto a transformar um estado de coisas que se lhe impôs.

14 Cf. FOUCAULT, Michel. Nietzsche, a genealogia e a história: In: FOUCAUL, Michel. Microfísica do poder. Organização e tradução de Roberto Machado. Rio de Janeiro: Edições, Graal, 1979, p. 28.

Filosofia e Educação - ISSN 1984-9605 - Volume 4, Número 2

Outubro de 2012 - Março de 2013 